\title{
EDUCACIÓN
}

\section{Estrategias metodológicas y competencias del docente utilizadas en el proceso de enseñanza- aprendizaje de la carrera de Odontología en una universidad privada}

\author{
Fanny Graciela Ayala Ratti ${ }^{1}$, María Eugenia Ayala Pereira ${ }^{1}$
}

\begin{abstract}
Resumen
Introducción: El proceso educativo se debe orientar hacia el aprendizaje permanente del estudiante universitario: como investigar, resolver problemas y comunicar. Este enfoque requiere del desarrollo de habilidades y competencias por parte del docente, así como métodos para incorporar elementos claves, uso de fuentes y recursos de información. En este sentido, cabe resaltar que una buena estrategia metodológica aplicada durante la labor, genera en el educando un aprendizaje eficaz y eficiente, lo cual permite construir una convivencia intersubjetiva entre docente y estudiante, porque, atendiendo específicamente a la carrera, objeto de este estudio, es menester mencionar que el papel del odontólogo en la sociedad es importante como agente de salud y para ello debe estar capacitado adecuadamente y, desde este estado, se puede apuntar a la construcción de un aprendizaje integral de las personas: un enfoque holístico. También se puede decir que esta forma de enfocar el aprendizaje requiere del desarrollo de habilidades y competencias por parte del docente, así como métodos para incorporar elementos claves y el uso de fuentes y recursos de información. Este trabajo fue presentado como tesis para la titulación de Magíster en Educación Superior con énfasis en Pedagogía. El estudio resultó relevante por el hecho de que el tema en cuestión necesita ser analizado con minuciosidad debido al desarrollo constante de las estrategias de enseñanza-aprendizaje que deben aplicarse dentro del constante avance y desarrollo de los conocimientos y tecnologías en el área odontología. Vale decir, que es importante acompañar los descubrimientos en todas las áreas científicas y en especial en las ciencias de la salud.
\end{abstract}

Objetivo: Describir las estrategias metodológicas utilizadas por docentes durante el proceso de enseñanza-aprendizaje en la carrera de Odontología de la Universidad del Pacífico Privada.

Material y Método: Se realizó un estudio de tipo descriptivo y para las variables se utilizó el criterio curricular de la carrera estudiada de modo holístico. Se

\footnotetext{
1. Universidad María Auxiliadora (UMAX), Paraguay.

Tesis presentada para optar el título de Magíster en Educación Superior con énfasis en Pedagogía, Universidad del Pacífico Privada.

E-mail: fananayalar@gmail.com
}

DOI: 10.26885/rcei.foro.2017.76 


\section{Estrategias metodológicas y competencias del docente. Ayala Ratti y Ayala Pereira}

realizaron entrevistas, encuestas y observaciones de clase. Una vez finalizada esta etapa se procedió a clasificar los datos. Los criterios de exclusión se condicionaron por la no participación o por ausencia del docente en periodo de la aplicación del estudio.

Resultados: Los hallazgos demostraron que la estrategia más utilizada es la clase en la carrera es la clase magistral y, en segundo lugar, la demostración práctica. La dramatización fue la estrategia menos seleccionada. Igualmente, el uso del lenguaje corporal fue la capacidad menos mencionada durante el estudio. Se observó que el 98,9\% de los docentes, (IC95\%=94-100\%), utiliza la clase magistral. El 20,9\% de los entrevistados menciona la utilización de otras estrategias, sin mención específica de las mismas. Las capacidades que los docentes evaluados perciben como necesarias para el desarrollo de las clases prácticas es la tutoría personalizada. Asimismo, la mayor parte de los encuestados mocionó a la creatividad $(85-93,4 \% /$ IC95\%=86,2-97,5) y el conocimiento y uso del vocabulario técnico $(84-92,3 \% /$ IC95\%=84,4-86,9) como herramientas necesarias. Pocos docentes involucran a los estudiantes en actividades de investigación: $71 \%$ de los encuestados (64) declaró no realizar trabajo de investigación (IC95\%=59,8-79,5).

Conclusiones: Los docentes de la Universidad del Pacífico Privada de la Carrera de Odontología realizan un buen trabajo, pero necesitan algunos ajustes con respecto a la utilización de TICs y el Aprendizaje Basado en Problemas (ABP), sugerido como metodología en esta área. Teniendo en cuenta las necesidades, es necesario que el docente universitario tenga presente que su labor es trascendental en la formación del futuro profesional, y más aún, esa labor debe apuntar a la formación de personas íntegras para que al lanzarse a la sociedad, tenga en cuenta su condición profesional y su condición de persona que está al servicio de las personas. Asimismo, se puede recomendar, por los hallazgos de este estudio que las universidades, deben acompañar a sus docentes a adquirir competencias metodológicas y estrategias más relevantes para acompañar eficientemente la formación de sus estudiantes. En este sentido es necesario establecer un presupuesto de inversión en la formación continua de los docentes de modo que con frecuencia se beneficien con capacitaciones como talleres y seminarios de modo que puedan estar constantemente actualizados y colaboren en el logro del perfil del egresado que tiene la institución universitaria. Asimismo, para lograr resultados auspiciosos en la formación de los estudiantes, se presenta como herramienta particular a aplicar a los estudiantes para el desarrollo de su proceso de aprendizaje y desarrollo integral la estrategia del ABP. Esto es relevante por el hecho de que puede ser encarado para todas y cada una de las asignaturas que conforman el universo de estudios. El ABP motiva un aprendizaje sustentado en el constructivismo. Y lo cual es importante porque en el proceso de desarrollo del aprendizaje es importante apuntar que los educandos crezcan dentro de un marco de la cooperación y la solidaridad. Esto, más allá de lo que puede aprender el educando dentro de la 
universidad para su competencia profesional, ya va con enfoque a ese objetivo, pues el aprender dentro de un ambiente cooperativo podrá orientar al futuro profesional a insertarse en la sociedad como una persona con mentalidad de servicio y con valores humanos necesarios para la construcción de una sociedad más reflexiva y solidaria.

Palabras clave: estrategias metodológicas, docente, formación, proceso enseñanza aprendizaje.

\section{RefERENCIAS}

Benvenuto, V. A. (2004). Las tecnologías de información y comunicaciones (TIC) en la docencia universitaria. Teoría, 12, 109-118.

Castañeda, L. (1986). Destrezas académicas básicas. México: Departamento de Psicología Educativa.

Delors, J. (1996). La educación encierra un tesoro. París: UNESCO, Comisión Internacional sobre la Educación para el Siglo XXI

Díaz Barriga, F. (2006). Enseñanza situada: vínculo entre la escuela y la vida. México: McGraw-Hill.

Mattheos, N., Schittek, M. J., Nattestad, A., Shanley D. \& Attstrom, R. (2005). Evaluación comparativa de la literatura de computación en la educación dental, los educadores y estudiantes. European Journal of Dental Education.

Marthaler, T (2001) Tendencias y perspectivas de la caries dental en el mundo. Nuevos criterios de diagnóstico, prevención y tratamiento de la caries dental. Buenos Aires: Asociación Argentina Odontológica.

Perinat, A. (2004). Conocimiento y educación superior: nuevos horizontes para la Universidad del Siglo XXI. sl: Editorial Paidós Ibérica. 